\title{
Electron-Impact-Induced 3,3-Sigmatropic Rearrangement and Cyclization in Phenyl Allenylmethyl Ethers
}

\author{
D. V. Ramana, K. K. Balasubramanian, M. S. Sudha and \\ T. Balasubramanian \\ Department of Chemistry, Indian Institute of Technology, Madras 600 636, India
}

A 3,3-sigmatropic rearrangement in the $\mathrm{M}^{+\cdot}$ of phenyl allenylmethyl ether is proposed for the observed losses of $\mathrm{CO}, \mathrm{C}_{2} \mathrm{H}_{4}$, and $\mathrm{CH}_{3}$. Direct cyclization in the $\mathrm{M}^{+\cdot}$ also leads to the $\left[\mathrm{M}-\mathrm{CH}_{3}\right]$ ion. The presence of sulfur as the heteroatom in phenyl allenylmethyl sulfide does not significantly influence the occurrence of Claisen rearrangement. Ortho interaction of the nitro group with the allenyl double bond in the side chain leads to characteristic fragment ions in 2-nitrophenyl allenylmethyl ether. Linked scans, high-resolution mass spectrometry, collision-activated dissociation-B/E linked-scan spectra, and D-labeling have been employed to support the proposed mechanisms and ion structures. (J Am Soc Mass Spectrom 1995, 6, 195-201)

A $\mathrm{s}$ in solution chemistry, 3,3-sigmatropic rearrangement that occurs in the gas phase has been well established [1]. Claisen rearrangement is reported to produce abundant $[\mathrm{M}-\mathrm{CO}]$ ion in phenyl allenyl ether [2] and fairly abundant [M $\mathrm{CO}$ ] ion in phenyl propargyl ether [3] on electron impact. Phenyl allyl ether [4] undergoes competing eliminations of $\mathrm{CO}$ and $\mathrm{C}_{2} \mathrm{H}_{4}$ from the quasimolecular ion under positive chemical ionization $(\mathrm{CI})$ conditions for which a Claisen rearrangement in $\left[\mathrm{MH}^{+}\right]$has been proposed. Amino- [5, 6] and thio- [7] Claisen rearrangements also are known in the gas phase.

In solution chemistry, phenyl allenylmethyl ethers are reported $[8,9]$ to undergo Claisen rearrangement, which gives rise to 4-methyl-2H-1-benzopyran and 2(o-hydroxyphenyl) buta-1,3-diene, and cyclization under catalyzed conditions [10] with mercuric trifluoroacetate to yield 4-exomethylene-3,4-dihydro-2H-1benzopyran. Phenyl allenylmethyl ethers also undergo Claisen rearrangement under electrochemical conditions [11] through a cation radical intermediate. However, there are no reports on the behavior of the cation radical of phenyl allenylmethyl ether generated under electron ionization (EI) conditions.

The nitro group and methoxy functions present in the ortho position can interact efficiently with the side chain in aromatic compounds during mass spectral decomposition. Nitro and methoxy groups are capable of transferring oxygen and hydrogen, respectively, to double bonds [12, 13], carbon-carbon triple bonds [14, $15]$, and heteroatoms $[16,17]$ in the side chain of the

Address reprint requests to Professor D. V. Ramana, Department of Chemistry, Indian Institute of Technology, Madras 600636, India. aromatic ortho disubstituted compounds, which affords diagnostically useful fragment ions. The nitro group also is reported $[2,18]$ to interact with the allenyl double bond to yield important fragment ions.

Hence, it was considered of interest to study the occurrence of Claisen rearrangement and the ortho interactions of the nitro and the methoxy substituents with the homoallenyl double bond in substituted phenyl allenylmethyl ethers (compounds 1-13; see Structure 1) under EI conditions.

\section{Results and Discussion}

The general fragmentation processes noticed in compound 1 under electron ionization condition are shown in Scheme I.

The base peak in the mass spectrum of phenyl allenylmethyl ether (1) is the ion at $m / z 94$ (Figure 1). A high-resolution study reveals the elemental composition of ion $a$ at $m / z 94$ to be $\mathrm{C}_{6} \mathrm{H}_{6} \mathrm{O}$ and a phenol radical cation structure has been assigned to $a$, which is envisaged to be formed by the $\beta$-hydrogen shift from the side chain to the oxygen (Scheme II). The proposed direct formation of ion $a$ from the $\mathrm{M}^{+\cdot}$ of 1 is supported by linked-scan studies (Table 2).

The most interesting fragment in the mass spectrum of 1 is the ion at $m / z 118$ (Scheme I, Table 1, and Figure 1) formed by the loss of $28 u$ from the molecular ion. High-resolution studies reveal that the fragment at $\mathrm{m} / z 118$ is a mixture of two ions $e$ and $f$ (Scheme III) in the ratio of $1: 0.88$ with the elemental compositions of $\mathrm{C}_{9} \mathrm{H}_{10}$ and $\mathrm{C}_{8} \mathrm{H}_{6} \mathrm{O}$ corresponding to $[\mathrm{M}-\mathrm{CO}]^{+\cdot}$ and $\left[\mathrm{M}-\mathrm{C}_{2} \mathrm{H}_{4}\right]^{+}$, respectively. The $\mathrm{B} / \mathrm{E}$ 
<smiles>[R]c1ccc(OCC=C=C)c([R])c1</smiles>

Compound No $R^{1} \quad R^{2}$

1 H H

$2 \quad \mathrm{OCH}_{3} \quad \mathrm{H}$

$3 \mathrm{H} \quad \mathrm{OCH}_{3}$

$4 \quad \mathrm{CH}_{3} \quad \mathrm{H}$

H

$5 \quad \mathrm{H} \quad \mathrm{CH}_{3}$

$6 \quad \mathrm{Cl} \quad \mathrm{H}$

$\begin{array}{lll}7 & \mathrm{Cl}\end{array}$

$8 \quad \mathrm{NO}_{2} \quad \mathrm{H}$<smiles>C=C=CCSc1ccccc1</smiles>

9

10<smiles>C=CC=CCOc1cccc2ccccc12</smiles>

15<smiles>C=C=CCOc1cccc([18O])c1</smiles><smiles>C=CC(=C)c1ccccc1O</smiles><smiles>C=C=CCOc1ccc2ccccc2c1</smiles><smiles>CC1=CCOc2ccccc21</smiles><smiles>C=C1CCOc2ccccc21</smiles>

linked-scan spectrum of the molecular ion of 1 and $\mathrm{B}^{2} / \mathrm{E}$ linked-scan spectrum of the ion at $m / z 118$ reveal the direct formation of the ions at $m / z 118$ from the $\mathrm{M}^{+\cdot}$ (Table 2).

Drawing an analogy from the behavior of compound 1 in solution $[8,9,11]$ and from the mechanistic study for the formation of [M $-\mathrm{CO}$ ] ions in phenyl allenyl ethers [2], a 3,3-sigmatropic rearrangement in the $\mathrm{M}^{+\cdot}$ of 1 that leads to the butadiene intermediate $d$ is envisaged for the formation of both [M $-\mathrm{CO}]$ and $\left[\mathrm{M}-\mathrm{C}_{2} \mathrm{H}_{4}\right]$ ions (Scheme III). Expulsion of $\mathrm{CO}$ from

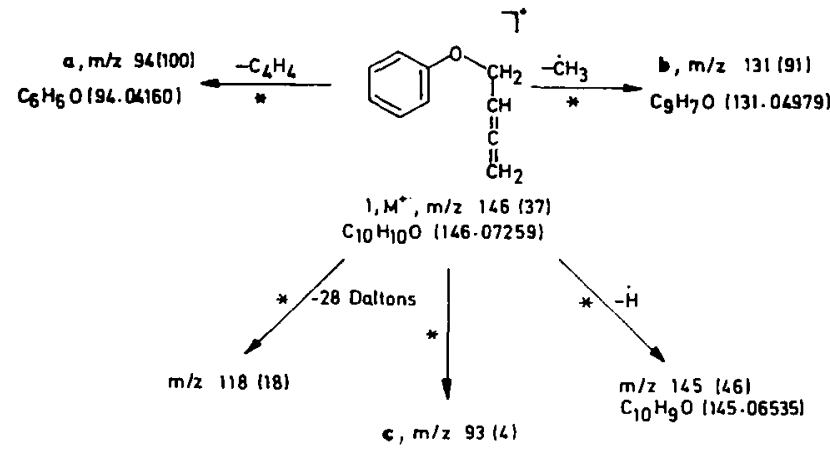

Scheme I

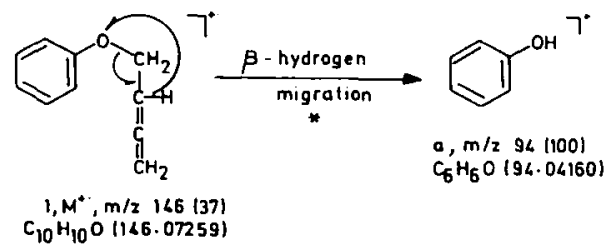

Scheme II

$d$ yields $e$. A hydrogen transfer from the ortho position of the phenyl ring to the double bond in the Claisenrearranged molecular ion $d$ followed by the expulsion of $\mathrm{C}_{2} \mathrm{H}_{4}$ is proposed for the formation of the ion $f$ (Scheme III). Beynon and co-workers [4] proposed a similar mechanism for the formation of $[\mathrm{MH}-\mathrm{CO}]$ and $\left[\mathrm{MH}-\mathrm{C}_{2} \mathrm{H}_{4}\right]$ ions in phenyl allyl ether under positive CI conditions.

It has been established that the thermally induced Claisen rearrangement $[8,9]$ of phenyl allenylmethyl ether (1) gives both 2-(o-hydroxyphenyl)buta-1,3-diene (14) and 4-methyl-2H-1-benzopyran (15). An investigation of the mass spectra of these compounds (Figure 1)

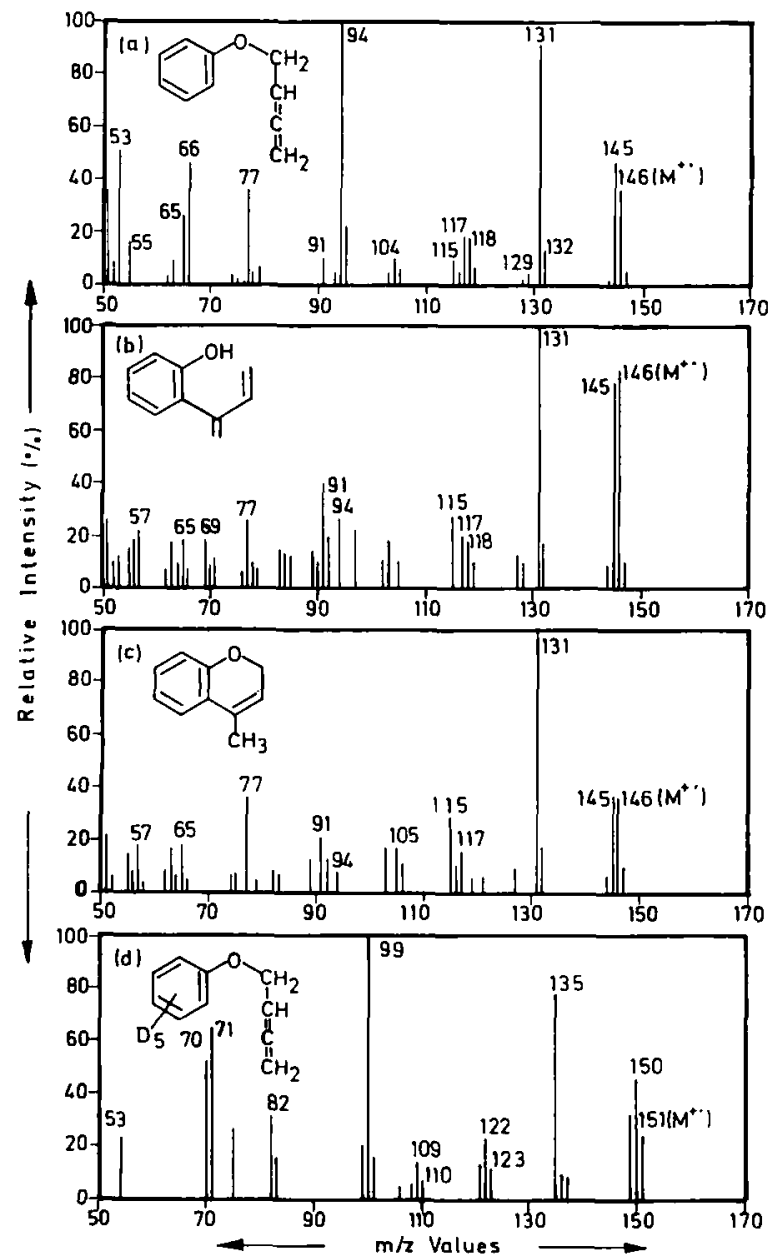

Figure 1. EI mass spectra at $70 \mathrm{eV}$ of (a) phenyl allenylmethyl ether (1), (b) 2-(o-hydroxyphenyl)buta-1,3-diene (14), (c) 4methyl-2H-benzopyran (15), and (d) ${ }^{2} \mathrm{H}_{5}$-phenyl allenylmethylether (13) 
Table 1. Partial mass spectra of compounds 2-12

\begin{tabular}{|c|c|c|c|c|c|c|c|}
\hline \multirow[b]{2}{*}{ Compound } & \multicolumn{7}{|c|}{ Mass-to-charge ratio values (relative abundance in parentheses) } \\
\hline & $\mathrm{M}^{+\cdot}$ & {$[\mathrm{M}-\mathrm{H}]^{+}$} & {$[M-R]^{+}$} & $a$ & $\begin{array}{l}{\left[\mathrm{M}-\mathrm{C}_{2} \mathrm{H}_{4}\right]^{+} /} \\
{\left[\mathrm{M}-\mathrm{CO}^{+\cdot}\right.}\end{array}$ & {$\left[\mathrm{M}-\mathrm{CH}_{3}\right]^{+}$} & Other ions \\
\hline 2 & $176(31)$ & $175(9)$ & $145(22)$ & $124(100)$ & - & $161(26)$ & $133(9), 123(5), 109(96)$ \\
\hline 3 & $176(27)$ & $175(7)$ & $145(6)$ & $124(100)$ & - & $161(26)$ & $122(35), 109(95)$ \\
\hline 4 & $160(29)$ & $159(11)$ & $145(62)$ & $108(100)$ & $132(5)$ & $145(62)$ & $107(65), 79(20)$ \\
\hline 5 & $160(23)$ & $159(7)$ & $145(49)$ & $108(100)$ & $132(3)$ & $145(49)$ & $107(72), 79(14)$ \\
\hline 6 & $180(11)$ & $179(4)$ & $145(43)$ & $128(100)$ & - & $165(6)$ & $127(3), 99(9)$ \\
\hline 7 & $180(14)$ & $179(3)$ & $145(98)$ & $128(100)$ & $152(1)$ & $165(5)$ & $127(4), 99(15)$ \\
\hline 8 & $191(5)$ & - & $145(3)$ & $139(100)$ & - & - & $123(11), 122(35)$ \\
\hline 9 & $191(4)$ & $190(1)$ & $145(11)$ & $139(43)$ & $163(1)$ & $176(10)$ & $174(100), 123(11)$ \\
\hline 10 & $196(100)$ & $195(49)$ & - & $144(64)$ & $168(8)$ & $181(50)$ & $\begin{array}{l}169(8), 143(8), 116(34) \\
115(44)\end{array}$ \\
\hline 11 & $196(75)$ & $195(41)$ & - & $144(100)$ & $168(14)$ & $181(44)$ & $169(20), 143(6), 116(23)$ \\
\hline 12 & $162(70)$ & $161(69)$ & - & $110(95)$ & $134(18)$ & $147(74)$ & $\begin{array}{l}130(12), 129(100), 128(33) \\
118(1), 109(35)\end{array}$ \\
\hline
\end{tabular}

reveals that the ions at $m / z 118$ that arise from the expulsion of both $\mathrm{C}_{2} \mathrm{H}_{4}$ and $\mathrm{CO}$ are present in the mass spectrum of 14 , but are totally absent in the mass spectrum of 15. Furthermore, a high-resolution study reveals the ion at $m / z 118$ in 14 to be a mixture of $[\mathrm{M}-\mathrm{CO}]$ and $\left[\mathrm{M}-\mathrm{C}_{2} \mathrm{H}_{4}\right]$ ions as observed in the case of 1 . These observations support the proposed Claisen rearrangement in the $\mathrm{M}^{+*}$ of 1 to ion $d$ before eliminating $\mathrm{CO}$ and $\mathrm{C}_{2} \mathrm{H}_{4}$.

Expulsion of a methyl radical from the molecular ion of 1 , which gives rise to an intense ion $b$ (Scheme I) at $m / z 131$, is another important mode of fragmentation as noticed in the mass spectrum of 1 (Figure 1 and Table 1). Based on collision-activated dissociation (CAD) studies, a benzopyrilium cation structure has been assigned to ion $b$ (Figure 2). Cyclization followed by the transfer of the aromatic hydrogen in the ion $d$ is proposed for the formation of the cyclic ion $g$, which then loses a methyl radical to produce $b$ at $\mathrm{m} / z 131$
(Scheme III). The formation of the $\left[\mathrm{M}-\mathrm{CH}_{3}\right]$ ion in 1 also can be visualized through a direct cyclization in the molecular ion that leads to the distonic intermediate $j$, which then rearranges to $g$ before expelling a methyl radical to form $b$ at $m / z 131$ (Scheme IV).

The proposed fragmentation mechanisms for the loss of $\mathrm{CH}_{3}$ from the molecular ion of $\mathbf{1}$ is corroborated by the fact that the ${ }^{2} \mathrm{H}_{5}$ compound 13 loses only $\dot{\mathrm{C}} \mathrm{H}_{2} \mathrm{D}$ from its $\mathrm{M}^{+*}$, which affords an abundant ion at $m / z 135$ in its mass spectrum (Figure 1). The fragmentation pathways envisaged for the formation of the $\left[\mathrm{M}-\mathrm{CH}_{3}\right]$ ion gain further support from the fact that the $\mathrm{CAD}-\mathrm{B} / \mathrm{E}$ linked-scan spectra (Figure 2) of the ions at $m / z 131$ from 1,14 , and 15 are identical with that from $2 \mathrm{H}-1$-benzopyran taken as the reference compound. It is clear from this observation that the $\mathrm{M}^{+\cdot}$ of 1 rearranges to the molecular ions of 14 and 15 before losing $\dot{\mathrm{C}} \mathrm{H}_{3}$ (Schemes III and IV).

Another interesting fragment ion in the mass spec-

Table 2. $\mathrm{B} / \mathrm{E}$ and $\mathrm{B}^{2} / \mathrm{E}$ linked-scan spectral data of compounds 1,8 , and 9

\begin{tabular}{|c|c|c|c|c|}
\hline \multirow[b]{2}{*}{ Compound } & \multicolumn{2}{|r|}{$B / E$} & \multicolumn{2}{|r|}{$B^{2} / E$} \\
\hline & $\begin{array}{l}\text { Parent ion } \\
m / z\end{array}$ & $\begin{array}{l}m / z \text { values of daughter ions } \\
\text { (relative abundance, } \% \text { ) }\end{array}$ & $\begin{array}{l}\text { Daughter ion } \\
\qquad / z\end{array}$ & $\begin{array}{l}m / z \text { values of parent ions } \\
\text { (relative abundance, } \% \text { ) }\end{array}$ \\
\hline \multirow[t]{6}{*}{1} & $M^{+}, 146$ & $17(145), 100(131), 32(119)$, & 145 & $100(146)$ \\
\hline & & $75(118), 83(117), 33(94)$ & 131 & $100(146)$ \\
\hline & & & 118 & $100(146)$ \\
\hline & & & 94 & $100(146)$ \\
\hline & & & 93 & $55(146), 60(145)$ \\
\hline & & & & $100(94)$ \\
\hline \multirow[t]{3}{*}{8} & $M^{+}: 191$ & $15(174), 80(161), 10(145)$ & 139 & $100(191)$ \\
\hline & & $100(139), 15(123), 12(122)$ & 122 & 25 (123), 22 (139). \\
\hline & & & & $100(191)$ \\
\hline \multirow[t]{2}{*}{9} & $\mathrm{M}^{+} ; 191$ & $\begin{array}{l}50 \text { (190). } 100(174), 28 \text { (145). } \\
94(139)\end{array}$ & 123 & $100(191)$ \\
\hline & 139 & $100(123)$ & & \\
\hline
\end{tabular}




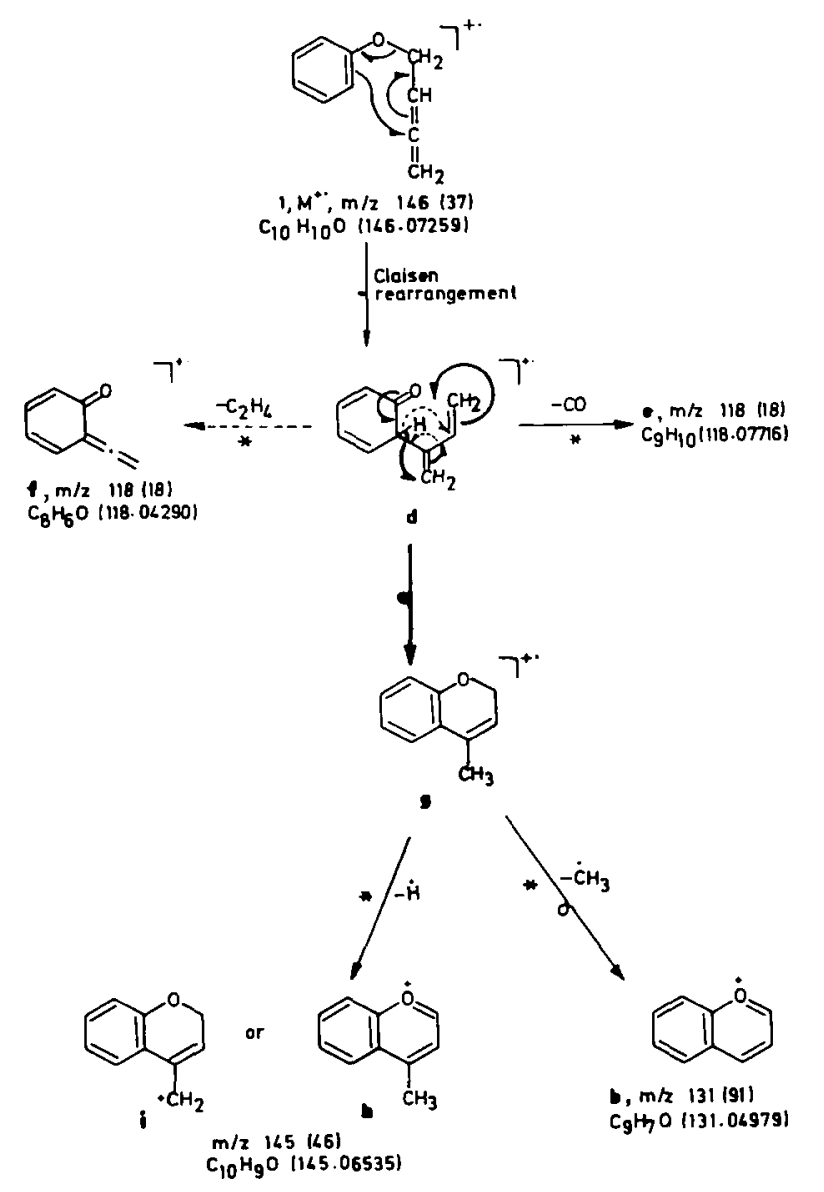

Scheme III

trum of 1 is the ion at $m / z 145$ formed by the expulsion of a hydrogen radical from the molecular ion (Figure 1 and Table 1). The hydrogen for the formation of the $[\mathrm{M}-\mathrm{H}]$ ion can originate from the homoallenyl carbon and also from the ortho position of the ring. The examination of the mass spectrum of the ${ }^{2} \mathrm{H}_{5}$ compound (13) (Figure 1) reveals that the ratio of the ionic abundances of $[\mathrm{M}-\mathrm{H}]$ and $[\mathrm{M}-\mathrm{D}]$ is $1: 0.76$ after isotopic correction.

The loss of a hydrogen radical from the carbon $\alpha$ to the oxygen in the ion $g$ would lead to the 4-methylbenzopyrilium cation $h$ (Scheme III), whereas the expulsion of a hydrogen radical from the methyl group would lead to the allylic cation $i$ (Scheme III). The elimination of a hydrogen radical from the ortho position of the ring can be explained through a direct cyclization process that leads to $j$ as shown in Scheme IV. Expulsion of an ortho hydrogen in $j$ yields the ion $k$ at $m / z 145$ (path A of Scheme IV). Ejection of a hydrogen radical from the homoallenyl carbon would lead to the ion $l$ (path B of Scheme IV).

It is noticed also that substituents from the molecular ions of compounds 2, 4, 6, and 7 are lost, which leads to abundant ions at $m / z 145$ (Table 1). The CAD-B/E linked-scan spectra (Figure 3 ) of the ions at $m / z 145$ from compounds 6 and 7 are found to be

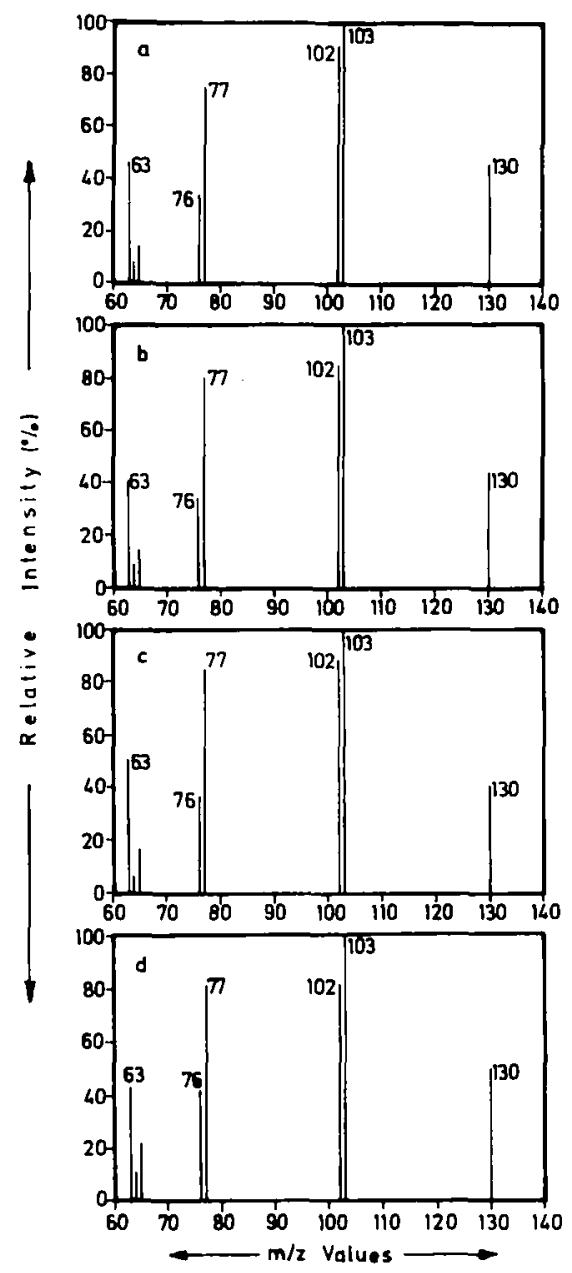

Figure 2. $\mathrm{CAD}-\mathrm{B} / \mathrm{E}$ linked-span spectra of the ions at $m / z 131$ from (a) phenyl allenylmethyl ether (1), (b) 2H-1-benzopyran, (c) 2-(o-hydroxyphenyl)buta-1,3-diene (14), and (d) 4-methyl-2Hbenzopyran (15).

identical with those from compounds 15 and 16, which indicates that the loss of substituent from the molecular ions of 6 and 7 and $[\mathrm{M}-\mathrm{H}]$ ions from 15 and 16 afford similar ion structures that correspond to $h$ (Schemes III and IV).

Interestingly, compounds 10 and 11 behave like compound 1 and give rise to significantly abundant ions that correspond to Claisen rearrangement (Table $1)$.

\section{Ortho Effect}

No fragment ion that corresponds to the ortho interaction of the methoxy group with the allenyl double bond is observed in the mass spectrum of 2-meth oxyphenyl allenylmethyl ether (2).

Evidence for the ortho interaction of the nitro group with the side chain is adduced by the presence of ions at $m / z 123$ and $m / z 122$ in the mass spectrum of 2-nitrophenyl allenylmethyl ether (8). An oxygen transfer from the nitro group to the allenyl carbon is envis- 


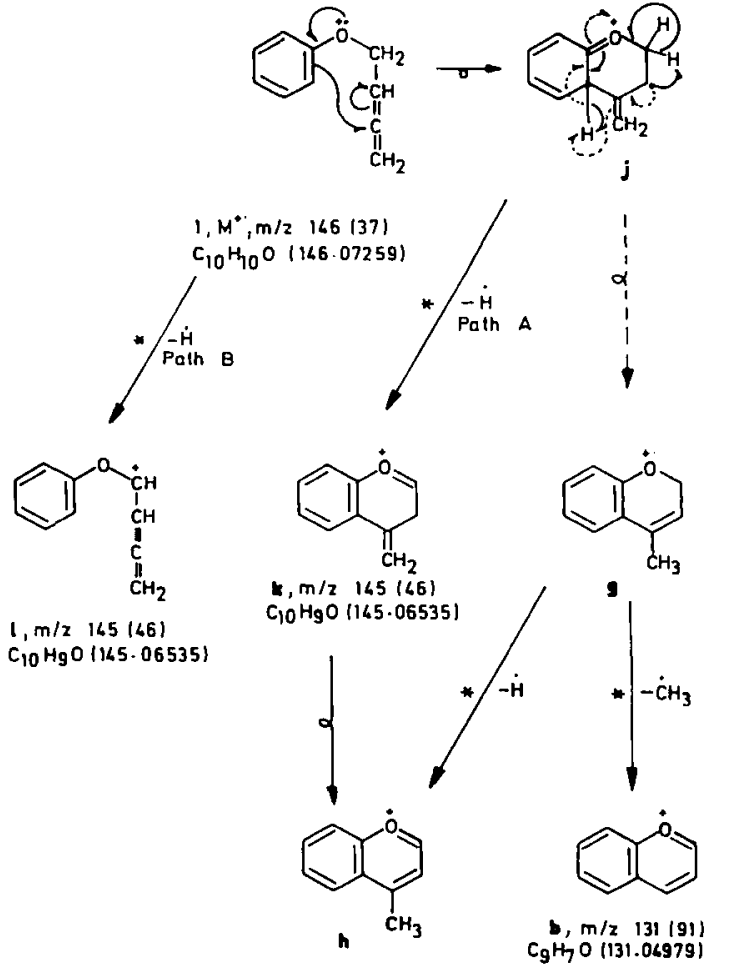

Scheme IV

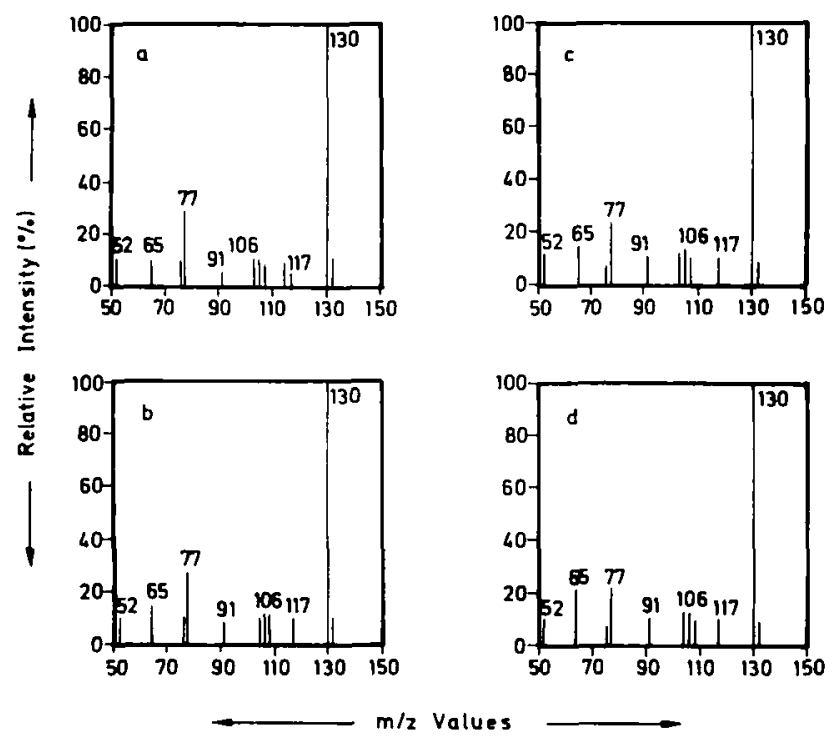

Figure 3. CAD-B/E linked-scan spectra of the ions at $m / z 145$ from (a) 4-methyl-2H-benzopyran (15), (b) 4-exomethylene-3,4dihydro-2H-1-benzopyran (16), (c) 2-chlorophenyl allenylmethyl ether (6), and (d) 4-chlorophenyl allenylmethyl ether (7).

aged for the formation of the rearranged molecular ion $m$ (Scheme V). A $\beta$-hydrogen migration in $m$ affords $n$ at $m / z$ 123. Loss of a hydrogen radical from $n$ gives rise to $o$ at $m / z$ 122, which is also formed directly from $m$ as revealed by the corresponding metastable transitions (Table 2).

Another pathway for the formation of 0 is by the expulsion of a hydroxy radical from the ion $a$ at $\mathrm{m} / \mathrm{z}$
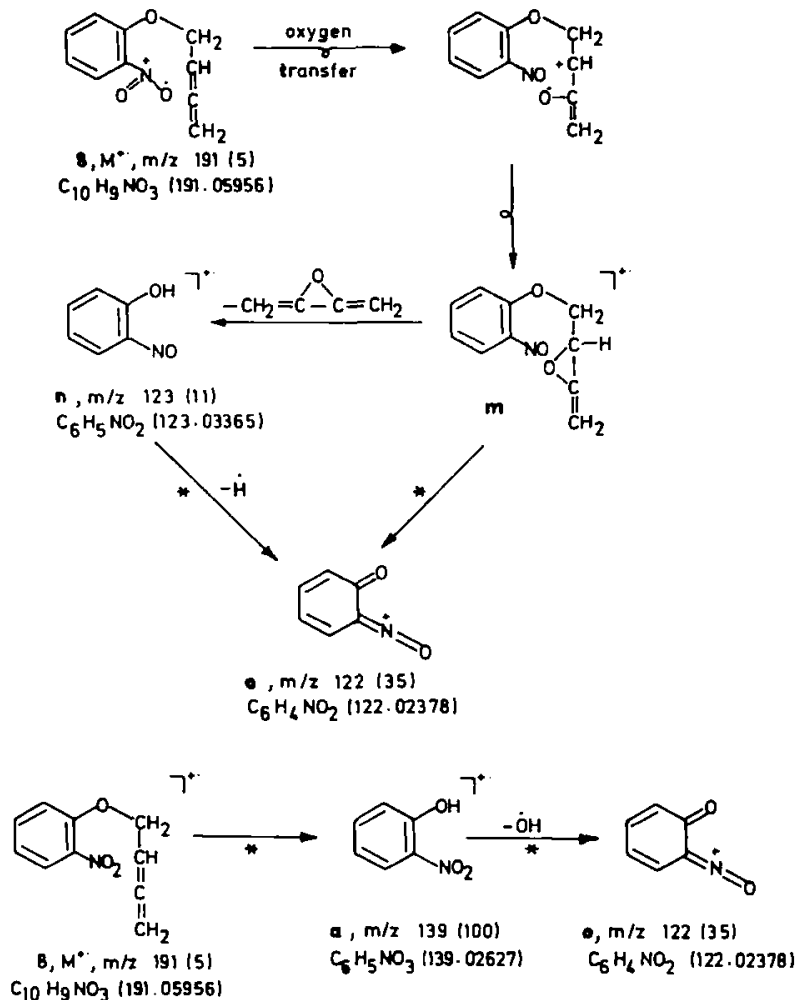

Scheme V

139 to give a product that corresponds to the base peak in the mass spectrum of $\mathbf{8}$. The fragment ion at $m / z$ 123 also is noticed in the mass spectrum of compound 9. The high-resolution data and linked-scan spectra (Table 2) reveal that the ion at $m / z 123$ in compound 9 is formed by the elimination of $\mathrm{O}$ from $a$ at $m / z 139$. The proposed structure for the ion $o$ at $m / z 122$ in compound $\mathbf{8}$ is supported by the CAD-B/E linked-scan studies (Figure 4 ).

\section{Thio-Claisen Rearrangement}

Interestingly, the mass spectrum of phenyl allenylmethyl sulfide (12) (Table 1) also contains peaks that correspond to $\left[\mathrm{M}-\mathrm{C}_{2} \mathrm{H}_{4}\right],[\mathrm{M}-\mathrm{CS}]$, and $\left[\mathrm{M}-\mathrm{CH}_{3}\right]$ ions. By inference from the behavior of its oxygen analog, a thio-Claisen rearrangement in the $\mathrm{M}^{+\cdot}$ of $\mathbf{1 2}$ that leads to the rearranged molecular ion $p$ is visualized for the formation of these ions (Scheme VI). Expulsion of a CS molecule from the ion $p$ gives rise to the ion $q$ at $m / z 118$, whereas ejection of $\mathrm{C}_{2} \mathrm{H}_{4}$ from $p$ yields the ion $r$ at $m / z$ 134. Elimination of a methyl radical from another rearranged molecular ion $s$ affords $t$ at $m / z$ 147. A benzothiopyrilium cation structure has been assigned to the ion $t$ based on the comparison of the CAD-B/E linked-scan spectrum of the ion $t$ from 12 and that of the ion at $m / z 147$ from $2 \mathrm{H}-1$-benzothiopyran; these spectra are found to be identical.

It can be noticed that the ejection of CS from the 


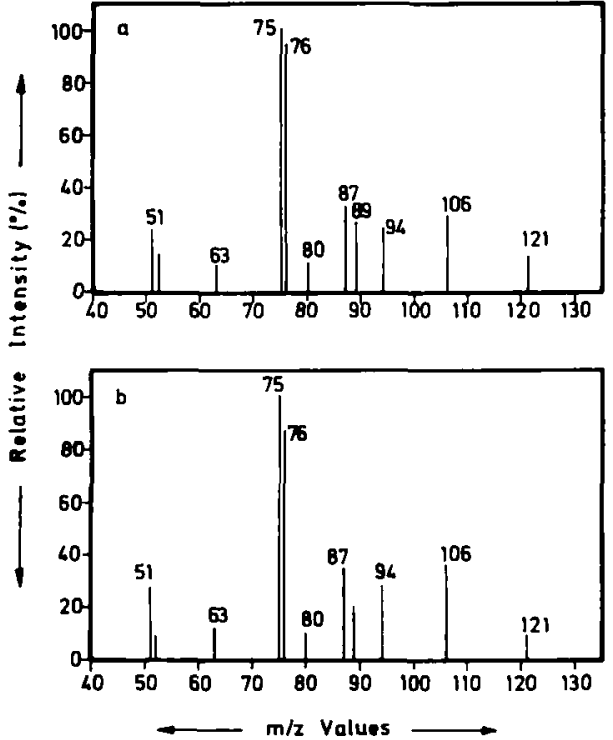

Figure 4. $C A D-B / E$ linked-scan spectra of (a) ion at $m / z 122$ from 8 and (b) ion at $m / z 122$ from $o$-nitrophenol.

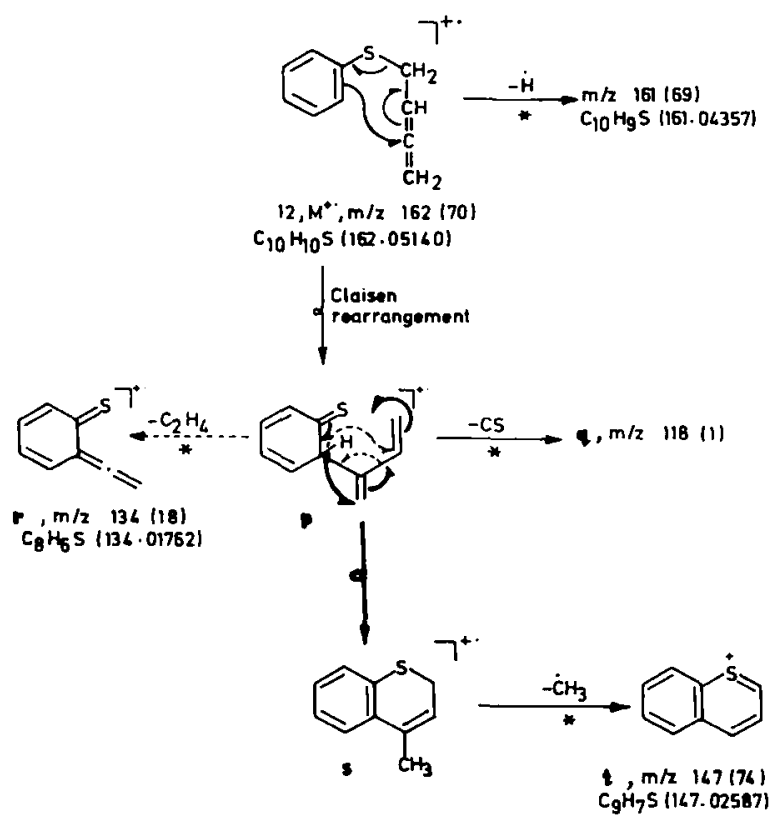

Scheme VI

$\mathrm{M}^{+\cdot}$ of 12 , which corresponds to the expulsion of $\mathrm{CO}$ from the $\mathrm{M}^{+\cdot}$ of 1 , leads to a very low abundance [M-CS] ion $q$ at $m / z 118$. This can be attributed to the higher heat of formation of CS. Hence, it can be inferred that the loss of CS from the $\mathrm{M}^{+\cdot}$ cannot be taken as measure of Claisen rearrangement.

It can be concluded from this study that the occurrence of Claisen rearrangement in phenyl allenylmethyl ether is manifested by the presence of fragment ions that correspond to $[\mathrm{M}-\mathrm{CO}],\left[\mathrm{M}-\mathrm{C}_{2} \mathrm{H}_{4}\right]$, and $\left[\mathrm{M}-\mathrm{CH}_{3}\right]$ ions in its mass spectrum. Direct cyclization in the $\mathrm{M}^{+\cdot}$ followed by the expulsion of methyl
Table 3. High-resolution mass spectrometry (HRMS) data for the molecular ions of new compounds 4,6 , and 8

\begin{tabular}{cccc}
\hline & \multicolumn{2}{c}{ HRMS data } & \multicolumn{2}{c}{$\begin{array}{c}\text { Elemental } \\
\text { compound }\end{array}$} & Observed & Calculated & \multicolumn{1}{c}{} \\
\cline { 2 - 4 } & composition \\
\hline \hline $\mathbf{4}$ & 160.08791 & 160.08882 & $\mathrm{C}_{11} \mathrm{H}_{12} \mathrm{O}$ \\
$\mathbf{8}$ & 180.03460 & 180.03419 & $\mathrm{C}_{10} \mathrm{H}_{9} \mathrm{ClO}$ \\
$\mathbf{8}$ & 191.05956 & 191.05825 & $\mathrm{C}_{10} \mathrm{H}_{9} \mathrm{NO}_{3}$ \\
\hline
\end{tabular}

radical also leads to $\left[\mathrm{M}-\mathrm{CH}_{3}\right]$ ion. The thio analog of compound 1 behaves similarly toward Claisen rearrangement as that noticed in the case of 1 . Although no ortho effect of the methoxy group with the allenyl double bond pertains to compound 2, fragment ions due to ortho interaction of the nitro group with the allenyl function are observed in ortho nitro compound 8.

\section{Experimental}

Compounds 1-13 were prepared in accordance with the procedures previously reported $[8,9]$ for the preparation of phenyl allenylmethyl ether. Compounds 14, 15 , and 16 were prepared according to the literature procedures $[9,10]$. Compounds 4,6 , and 8 were not previously reported. All the compounds were purified by column chromatography with neutral alumina and hexane as the eluent. The structures were confirmed by infrared ${ }^{1} \mathrm{H}$ NMR and high-resolution mass spectrometry (Table 3 ). Mass spectra were recorded on a Finnigan-MAT 8230 double focusing mass spectrometer (Finnigan-MAT, Bremen, Germany). The mass spectra were run at $70 \mathrm{eV}$ with an emission current of $100 \mu \mathrm{A}$ and an acceleration voltage of $3 \mathrm{kV}$. All the compounds were introduced into the mass spectrometer through either the reference inlet at $110^{\circ} \mathrm{C}$ or the direct insertion probe at $25^{\circ} \mathrm{C}$. The $\mathrm{CAD}-\mathrm{B} / \mathrm{E}$ linkedscan spectra in the first field-free region were investigated by using helium as the collision gas in a Finnigan-MAT 8230 mass spectrometer at an ionization energy of $70 \mathrm{eV}$ and an acceleration voltage of $3 \mathrm{kV}$. Accurate mass measurements were carried out at a resolution of $8000(10 \%)$ valley by using perfluorokerosene as the reference.

\section{Acknowledgments}

The authors thank the Regional Sophisticated Instrumentation Center, Indian Institute of Technology, Madras, for mass spectral facilities. MSS and TB thank Council of Scientific and Industrial Research, India, for research fellowships.

\section{References}

1. Lutz, R. P. Chem. Rev. 1984, 84, 205.

2. Ramana, D. V.; Sudha, M. S. Org. Mass Spectrom. 1992, 27, 1121.

3. Ramana, D. V.; Sudha, M. S. J. Chem. Soc. Perkin Trans. 2 1993,675 . 
4. Kingston, E. E.; Beynon, J. H.; Liehr, J. G.; Meyrant, P.; Flammang, R.; Maquestiau, A. Org. Mass Spectrom. 1985, 20, 351.

5. Kingston, E. E.; Beynon, J. H.; Liehr, J. G.; Meyrant, P.; Flammang, R.; Maquestiau, A. Org. Mass Spectrom. 1988, 23, 437.

6. Vandezonneville, A.; Flammang, R.; Maquestiau, A.; Kingston, E. E.; Beynon, J. H. Org. Mass Spectrom. 1986, 21, 351.

7. Ramana, D. V.; Sudha, M. S. Sulfur Lett. 1994, 17, 153.

8. Dikshit, D. K. Intim I. Che'm. Se'C. B 1983, 22, 1144.

9. Balasubramanian, T.; Balasubramanian, K. K. Tetrahedron Left. 1991, 32, 6641.

10. Balasubramanian, T.; Balasubramanian, K. K. I. Chem. Soc. Chcm. Commun. 1992, 1760.
11. Dhanalekshmi, S. Ph.D Thesis, Indian Institute of Technology, Madras, India, 1993.

12. Baldas, J.; Porter, Q. N.; Ramsay, C. C. R. Aust. J. Chem. 1969, 22, 405.

13. Ramana, D. V.; Vairamani, M. Org. Mass Spectrom. 1974, 9, 1158.

14. Ramana, D. V.; Ramakrishna, N. V. S. Org. Mass Spectrom. $1989,24,317$.

15. Ramana, D. V.; Ramakrishna, N. V. S. Org. Mass Spectrom. $1989,24,66$

16. Bowie, J. H.; Larsson, F. C. V.; Schroll, G.; Lawesson, S. O.; Cooks, R. G. Tetrahedron 1962, 23, 3743.

17. Schwarz, H.; Bohlmann, F. Org. Mass Spectrom. 1974, 9, 283.

18. Ramana, D. V.; Ramakrishna, N. V. S. Org. Mass Spectrom. 1992, 27, 515 . 